\title{
Razão e ética: práxis e governança global
}

\section{Reason and ethics: praxis and global governance}

Razón y ética: praxis y gobernanza global

\section{Resumo}

Este artigo fomenta a necessidade de pensar o agir humano, fonte de desenvolvimento sustentável - governança global - refletindo sobre os diversos aspectos do progresso participativo e compartilhado. Neste sentido, indaga-se: as ações e políticas governamentais, fomentam a cidadania, a dignidade da pessoa humana, o desenvolvimento que se associa a erradicação da pobreza? O objetivo consiste em explorar a razão e a ética enquanto elementos que possibilitem zelar da práxis necessária para a sustentabilidade global. Quanto à metodologia, a pesquisa é exploratória e analítica com abordagem qualitativa, sendo realizada por meio de revisão de literatura. Nesta perspectiva, conclui-se que, compreender a razão e a ética enquanto fundamento dos valores sobre os quais acontecem o agir humano é de fundamental importância para que se possa garantir o desenvolvimento sustentável. Ademais, destaca-se que as políticas públicas devem ser implementadas no sentido de promover a educação e formação da pessoa para que possa atuar proativamente. É necessário superar a exploração predatória e desenvolver uma nova sabedoria que suscite a praxis em prol de um desenvolvimento que envolva todos os seres humanos à família humana.

Palavras-chave: Sustentabilidade; Essência administrativa; Governança; Economicidade; Sociabilidade.

\begin{abstract}
This article encourages the need to think about human action, a source of sustainable development - global governance - reflecting on the various aspects of participatory and shared progress. In this sense, the question is: do government actions and policies promote citizenship, human dignity, development that is associated with the eradication of poverty? The objective is to explore reason and ethics as elements that make it possible to ensure the necessary praxis for global sustainability. As for the methodology, the research is exploratory and analytical with a qualitative approach, being carried out through a literature review. From this perspective, it is concluded that, understanding reason and ethics as the foundation of the values on which human action takes place is of fundamental importance to ensure sustainable development. Furthermore, it is highlighted that public policies must be implemented in order to promote the education and training of the person so that they can act proactively. It is necessary to overcome predatory exploration and develop a new wisdom that encourages praxis in favor of a development that involves all human beings in the human family.
\end{abstract}

Keywords: Sustainability; Administrative essence; Governance; Economy; Sociability.

\footnotetext{
${ }^{1}$ Grupo de Pesquisa: Homo Ad-minister

${ }^{2}$ PIBIC-UNIR - PVC419-2021 - Transferência de renda como inclusão: Análise sobre vulnerabilidade e direitos humanos. Edital No 2021/PIBIC/DPESQ/PROPESQ/2021

${ }^{3}$ Grupo de Pesquisa: Centro de Estudos Socioambientais - CECISA

${ }^{4}$ Grupo de Pesquisa: Inovação em Inteligência Artificial, Engenharia e Gestão - IAGEN
} 


\begin{abstract}
Resumen
Este artículo alienta la necesidad de pensar en la acción humana, fuente de desarrollo sostenible - gobernanza global reflexionando sobre los diversos aspectos del progreso participativo y compartido. En este sentido, la pregunta es: ¿las acciones y políticas gubernamentales promueven la ciudadanía, la dignidad humana, el desarrollo asociado a la erradicación de la pobreza? El objetivo es explorar la razón y la ética como elementos que permitan asegurar la praxis necesaria para la sostenibilidad global. En cuanto a la metodología, la investigación es exploratoria y analítica con enfoque cualitativo, realizándose a través de una revisión de la literatura. Desde esta perspectiva, se concluye que entender la razón y la ética como fundamento de los valores sobre los que se desarrolla la acción humana es de fundamental importancia para asegurar el desarrollo sostenible. Además, se destaca que se deben implementar políticas públicas que promuevan la educación y formación de la persona para que pueda actuar de manera proactiva. Es necesario superar la exploración depredadora y desarrollar una nueva sabiduría que incentive la praxis a favor de un desarrollo que involucre a todos los seres humanos de la familia humana.
\end{abstract}

Palabras clave: Sustentabilidad; Esencia administrativa; Gobernancia; Economía; Sociabilidad.

\title{
1. Introdução
}

Este artigo evidencia o ser humano como agente responsável pela práxis - na administração da sociedade, dos recursos e das relações interpessoais vinculando a esse a responsabilidade dos efeitos provocados pelo modo de gerir a governança. Elucidando que os agrupamentos humanos não são acidentes históricos, guarda-se por trás deles a necessidade humana de estar com semelhantes e o imperativo de sobrevivência fisiológica que depende do corpo/malha social, seja pela segurança que a comunidade proporciona seja pela produção de bens e mercadorias.

Deste modo, o télos não só do Estado, mas de toda coletividade humana é a promoção de maior conforto e bem estar, pressupõe níveis mais elevados de satisfação para as pessoas do que aqueles que são possíveis isoladamente. Por força da Constituição Federal de 1988, o Estado brasileiro fica responsabilizado pelo bem estar social e, neste sentido, indaga-se: as ações e políticas governamentais fomentam a cidadania, a dignidade da pessoa humana e o desenvolvimento que se associa a erradicação da pobreza?

A razão prática, aquela responsável por traçar os "caminhos do bem" para o bom agir individual no mundo tem a função de descrever os princípios que devem fundamentar os costumes de um povo, bem como sua consciência diante da humanidade. É relevante que seja valorizada a atuação que equilibra o auto interesse com os interesses sociais para que alcance o grau máximo de satisfação social, levando-se em consideração a existência do outro como um igual, mas que pode ser detentor de necessidades diferentes e, portanto, exige-se posicionamentos equitativamente diferentes por parte das instituições, sejam elas sociais ou estatais.

Dentre as políticas públicas implantadas com vistas a erradicação da pobreza e consequente fomento da cidadania, cita-se os programas de transferência de renda, que sem a pretensão de aprofundá-los neste trabalho, argumenta-se ser de fulcral importância para a ampliação das capacidades de consumo das famílias em condições de vulnerabilidade, promovendo sua condição de agente, com o objetivo que se amplie as possibilidades de transição para condições melhores, bem como a mobilidade social.

\section{Metodologia}

O presente artigo de revisão sustenta-se na prévia leitura e consequente análise de fontes bibliográficas afetas à temática objeto de estudo (razão e ética), o cominho metodológico observou o que descreve Severino (2016), de modo que a abordagem e o tratamento do objeto da pesquisa deve observar a leitura e análise de fontes documentais, disponíveis para a obtenção das categorias de análises, tendo por base a síntese e a estruturação conceitual de obras e artigos de diversos autores, que possibilitaram ampliar o entendimento sobre o tema. Quanto aos procedimentos, a pesquisa classifica-se como bibliográfica, quanto à natureza, básica ou teórica; quanto aos objetivos, exploratória e analítica e quanto ao método de abordagem, qualitativa (Gil, 2017). 
Nesta perspectiva, se observou textos e contextos de documento do pensamento social da igreja Católica, observando e analisando em uma perspectiva do economista Amartya Sen, bem como em observância a conceitos éticos-filosóficos. Foram observados documentos publicados pela igreja no período de 1981 à 2021, é notório a relevância dos conceitos observados, bem como se acentua a evolução dos mesmos, outrossim, é de se destacar a sincronia entre as obras analisadas. Ao se observar a forte influência do pensamento da Igreja na formação e na cultura social, se torna importante compreender, analisar e comparar esses elementos associando-os a obras e contextos específicos.

\section{Resultados e Discussão}

Refletir sobre a sociedade ideal sem pensar nas pessoas que são responsáveis por administrar essa sociedade, é um processo no qual se transforma a sociedade em 'seres mitológicos', distanciando-se da capabilidade humana de administrar sua própria forma de organização social, econômica e parental. Para administrar a sociedade tendo por base a pessoa, é preciso que o ser humano possa ser pensado em sua capabilidade de economicidade, de sociabilidade e de parentalidade. A indagação que paira é: seria possível envolver a família humana ao comprometimento com o qual se envolve com a parentalidade? Neste sentido, impera a necessidade de compreender melhor qual é mesmo a razão e qual é a ética sobre as quais se fomenta os valores que orientam o agir humano em sociedade.

\subsection{Razão e ética: por um agir autônomo}

Administrar os recursos econômicos se volta para a prática, para o mundo que resulta das ações humanas, mas que encontra seus pressupostos na razão. A práxis dos sistemas econômicos possuem motivações previamente estabelecidos que justificam sua existência sendo útil na medida em que atende os desejos humanos. No entanto, não se pode confundir que apontar os objetivos, as metas e a técnica para atingir os resultados significa, necessariamente, determinar os princípios que regem as atividades econômicas.

A elaboração dos princípios que funcionarão como os baluartes do agir deve envolver reflexões do que é melhor para a promoção da sociabilidade, do respeito, da economicidade e da construção e reconstrução dos direitos humanos. Os objetivos individualistas, as metas meramente quantitativas e as técnicas descompromissadas podem direcionar o agir, mas o bom agir exige a eleição de princípios fundamentados, antes de tudo, numa razão prática responsável, cordial e qualificada — dotada de qualidades, segundo João XXIII (1963, n 146), é possível salientar que é preciso "inserir-se nas suas instituições e trabalhá-las eficientemente por dentro" com a missão de "impregnarem de retas normas e princípios cristãos uma civilização", já que "não basta gozar da luz da fé e arder no desejo do bem".

Os princípios são os ideais fundamentais que direcionam os fins de ações futuras à sua elaboração e, permanecem sendo úteis à medida que são resgatados para dar sentido ao agir. Tais princípios não são dados pela natureza, mas sim construídos e reavaliados com a participação do outro, e como tal carecem de constante afirmação na prática. Ou seja, Amarya Sen, sugere que não basta erigir esses princípios, que são ao mesmo tempo a base em que se funda e a bússola que norteia a prática, e como tal devem ser materializados nas ações e nos resultados, sintetizando precisam influenciar, decisivamente o modo como o ser humano vive, não no sentido de controles e obrigação de fazer, mas no sentido de viver a liberdade como desenvolvimento.

Kant, em Crítica da razão pura e em Fundamentação da metafisica dos costumes, teoriza afirmando que a razão possui duas aplicações: a teórica e a prática. Então, para as ciências, no sentido teórico, a razão é aquela que determina os critérios e condições do conhecimento, os pressupostos, pois, a razão só pode compreender aquilo que ela mesma produz segundo seu projeto e, então, posteriormente o conhecimento é validado por aqueles pressupostos fornecidos pela razão. Assim, neste caso a razão teórica desempenha dupla função, sendo a primeira a de estabelecer os critérios de validade do 
conhecimento e a segunda, de conhecer a ciência.

Além do uso teórico, a razão também possui uso prático, que apontam os princípios norteadores das vontades humanas e das atividades que transformarão o mundo. Ações são morais quando atendem a imperativos impostos pela razão, ou nesse caso, a princípios levantados a partir de condicionantes éticas, de modo que "O critério de moralidade, para que seja universal e necessário, deve ter um ordenamento na razão" (Weber, 2013, p. 12). É preferível, portanto, atribuir à razão a autoria dos "caminhos do bem" do que a motivadores que se baseiam tão somente no mundo material e nas experiências mundanas ou, em outras palavras, ao lucro indolente, ao crescimento econômico desvinculado da ética, da valorização humana e do trabalhador somente na medida em que é útil para o capital e nos limites deste, na pujança de status, dentre outros.

Isto posto, infere-se que é na razão que se pode determinar os princípios morais responsáveis por guiar as vontades. Kant é radical nesse quesito, pois, para ele, a razão deverá estabelecer as leis que governam as vontades de uma tal maneira que as ações devem ser sempre pautadas por essas leis morais e, portanto, na razão e não por elementos particulares e contingentes das experiências, como salientou Weber (2013). Assim, a razão toma o espaço absoluto na práxis humana de forma que as vontades devem ser mera decorrência daquela. Quando o agente, finalmente, tem todas suas ações e vontades orientadas pelos fundamentos dispostos pela razão ele se tornou livre de fato. Sair de uma menoridade filosófica é poder se servir da própria razão, legislar as próprias leis e determinar seus objetivos e vontades condicionados pelos critérios de moralidade. Então o sujeito é autônomo quando cria as leis que segue e essas leis são válidas quando não forem imorais.

A radicalidade do papel da razão em Kant pode ser atualizada na medida em que se constrói as práxis passíveis de serem aplicadas num mundo contingente e disforme. Não se propõe o uso rígido da razão como absoluta, ao contrário, volta-se para o uso flexibilizado da capacidade da razão, pois se reconhece que não é possível transformar, em absoluto, o mundo material e dos fatos (o ser) no mundo idealizado pela razão (o dever-ser). No entanto, afirma-se que o mundo social é na mesma medida em que as pessoas também são, pois os humanos são dotados da capacidade de interferir e mudar o curso dos acontecimentos sociais, repousa aí a função da razão na elaboração de estruturas morais e condizentes com a dignidade. Valoriza-se o olhar para o futuro carregado pelas possibilidades e não pela resignação fatalista, busca-se a potência e o potencial de mudança, guiados por uma razão ética.

Kant ainda afirma que autonomia e dignidade estão fundamentalmente ligadas, de modo que não se pode falar de uma sem o outra. Dignidade é intrínseca à condição humana, devendo ser observada na práxis, sob pena de relativizar o valor humano real que é absoluto. Para fixar essa situação de absoluta dignidade, Kant elabora a segunda formulação do imperativo categórico ao afirmar que devemos agir de modo que tratemos nós mesmos e o restante da humanidade como fim em si mesmo. Não posso agir moral e racionalmente e, ao mesmo tempo, não perceber que todas as pessoas são fins nelas mesmas. Tratar o outro como fim em si mesmo é reafirmar a dignidade que faz parte de todos, é também garantir as condições de que o sujeito seja autônomo e que seja reconhecido o potencial de guiar-se por leis morais, pois as pessoas são dotadas de personalidade moral.

Decorre dessa assertiva que pessoas não são, e não devem ser, objetos, caminhos e instrumentos, pois isso seria o mesmo que negar a dignidade que é inerente ao ser capaz de razão. A todos é determinada tal ordem e todos são seus beneficiários e titulares, portanto, somos responsáveis por garantir tal imperativo. Nesse mesmo sentido, Weber (2013, p. 20) aponta que "A concepção mais nobre que se pode deduzir dessa formulação é a de que o homem é sujeito de direitos". Ser sujeito de direito compreende titularizar direitos e contrair obrigações em face de todos.

Portanto, a razão e o ser humano como seu senhor, ocupam o centro do conhecimento não sendo permitido - pelo princípio da moralidade e das formulações do imperativo categórico - que se utilize deste aparato para instrumentalizar os demais, mas tão somente em benefício da humanidade. O agir está condicionado aos imperativos morais da razão, pois agir moralmente é agir de acordo com motivações nobres e principiológicas. Impõe-se que a ação não seja desvinculada de seu 
conteúdo axiológico e/ou com pretensões neutras.

Todo esse arranjo moral deve ser considerado juntamente com os "outros", em comunidade, de modo que a construção de máximas morais encontre seu lugar na razão pública, de maneira que possam legislar as normas que governam seu agir, de tal forma que "Assim, poder-se-ia dizer que uma ação será efetivamente boa se qualquer um puder concordar com ela" (Weber, 2013, p.22) ao passo que o autor afirma ainda que "A possibilidade de um povo dar a si mesmo a própria lei é que define essa autonomia". O ser humano possui a capacidade da boa vontade e essa boa vontade é determinada pela dignidade intrínseca à vida humana, de modo que Kant qualifica a vontade ideal, aquela perseguida em comunidade, para que se caminhe na construção do "reino dos fins", que seja, uma sociedade sistematicamente interligada por leis sancionadas pela razão pública no desempenho de sua autonomia e com a participação livre e informada de todos. De outro modo, infere-se que o ser humano é igualmente capaz de uma má vontade, que motiva um mau agir, qual seja, apartado da racionalidade e vazio da busca pelo bem de si e de todos. Então, a humanidade pode estar no mundo de ambas as formas a depender das motivações que alimentam a vontade.

O ser humano vive sua própria dignidade à medida em que a dignidade é fundamentada pela autonomia. No entanto, há casos em que essa autonomia é negada ao sujeito, seja por motivações justas, como nas ocasiões em que alguém têm seu direito de liberdade devidamente suspenso como consequência de prática delituosa; mas, além disso, também é possível ter vetada sua autonomia por circunstâncias injustas e degradantes que degeneram a dignidade, como no caso das desigualdades sociais que vulnerabilizam pessoas, distanciando, portanto, de um proposito no qual "as múltiplas sociedades são chamadas a constituir um tecido unitário e harmônico, onde cada uma possa conservar e desenvolver a própria fisionomia e autonomia" (João Paulo II, 2004, nº 151).

Desta forma, entende-se que a autonomia e a dignidade estão radicalmente imbricadas uma à outra, ambas fazendo parte do ser humano. Idealmente considerado, o ser humano livre (autônomo e altero) é aquele que tem todas suas vontade e ações determinadas pelo princípio de moralidade de se servir de sua própria razão.

Outrossim, autonomia e, portanto, liberdade tem implicações nas possibilidades reais de determinar a vida que deseja levar e práticas naquilo que as pessoas substancialmente podem fazer. Então, em outras palavras, uma pessoa capaz é aquela que dispõe de um conjunto de fatores que torna possível ser autônomo para escolher como gostaria de viver, por isso, "O que as pessoas conseguem positivamente realizar é influenciado por oportunidades econômicas, liberdades políticas, poderes sociais e por condições habilitadoras como boa saúde, educação básica e incentivo e aperfeiçoamento de iniciativas" (Sen, 2010, p.18), em se tratando do assunto é preciso pontuar que:

O Estado, cuja razão de ser é a realização do bem comum na ordem temporal, não pode manter-se ausente do mundo econômico; deve intervir com o fim de promover a produção de uma abundância suficiente de bens materiais, 'cujo uso é necessário para o exercício da virtude'; e também para proteger os direitos de todos os cidadãos, sobretudo dos mais fracos. (João XXIII, 1961, nº 20).

Basear-se apenas - aqui abranda-se a tese kantiana - em indicativos empíricos para motivar as realizações é não desempenhar a autonomia que é intrínseca aos humanos. A personalidade moral depende que a vontade encontre seus fundamentos em princípios racionais, quando isso ocorre, o agente pode ser livre. Kant ainda sustenta que ao pautar-se nos ditames da segunda formulação do imperativo categórico (todos como um fim em si mesmos), promover-se-ia uma sociedade ideal, o reino dos fins, que requer uma abstração do conteúdo dos interesses particulares dos sujeitos (Weber, 2013) e em que todos tem livre acesso a razão pública e por consequência à dignidade. A esta perspectiva se chega a evidência de que os seres humanos "desencaminhados na inteligência ou pervertidos na vontade, se valem desses meios contra a razão, isto é, para fins que não correspondem à sua própria natureza social” (João XXIII, 1961, nº 198) 
No entanto, o "reino dos fins", em sua integralidade, não pode existir, é um dever-ser que precisa ser almejado e ambicionado, é modelo ideal capaz de inspirar a transformação da realidade por meio do uso da razão pública libertadora. A razão prática proposta é responsável e responsiva em face daquilo que provoca no mundo, não foge ao reexame das ações para promover resultados adequados aos princípios de moralidade, autonomia e dignidade, é na mudança e na possibilidade de traçar os "caminhos do bem" e no controle das paixões que a razão desempenha sua grande utilidade e é por meio da primazia humana que ela age.

\subsection{Governança global e o homo ad-minister}

Neste ponto é necessário elucidar o Homo Ad-minister, haja vista que por vezes se deseja a sociedade ideal, sem pensar nas pessoas que são responsáveis por administrar as sociedades. Pontua-se, portanto, sobre o ser humano como agente responsável por colocar em prática atitudes e políticas advindas de governanças que se fazem em prol do desenvolvimento sustentável. Foi suscitado, em primeiro momento, enquanto norte deste artigo a seguinte indagação: as ações e políticas governamentais fomentam a cidadania, a dignidade da pessoa humana e o desenvolvimento que se associa a erradicação da pobreza? Neste ponto, se observa a indagação sobre a parentalidade para suscitar que o modelo de governança existente na hodiernidade, sempre suscita um limite ao próprio agir humano, de forma que esse limite restringe a amplitude de nossas atitudes à parentalidade. Nossa responsabilidade é por sinal com nossos filhos, pais, cônjuges e enfim, nossa atitude de cuidado se restringe à parentalidade. É fato que se tem desequilíbrio entre essas duas dimensões da vida, parentalidade e família humana, para exemplificar, se deve ter clareza entre as necessidades, as possibilidades e os subsídios que se tem à disposição.

No entanto, a convivência em sociedade supera os limites da parentalidade e essa só se torna possível por conta do grupo maior que a comporta, não há isolamento absoluto entre o convívio familiar e a sociedade, pois aqueles que compõe a família integram, concomitantemente, outros grupos sociais, instituições e organizações. Há, portanto, uma necessária correspondência entre parentalidade e a comunidade e uma reciprocidade relacional. Ribeiro (2019, p. 11) fomenta que "de acordo com a sociologia, os indivíduos não são seres isolados competindo livremente uns com os outros para alcançar melhores posições sociais ao longo da vida", mas sim integram uma coletividade e "vivem em contextos que contribuem para moldar as oportunidades e chances que encontram para alcançar diversos bens e posições sociais ao longo da vida" (Ribeiro, 2019, p. 11).

É sobre a práxis humana que é formada por um conjunto de conhecimentos, habilidade e atitudes, que se desenvolve sobre uma base de sentimentos de pertença, e que por isso se direciona exclusivamente à parentalidade. Deste modo a moral familiar torna a distância entre ética e economia ainda maior, para o entendimento sobre esse assunto recorre-se primeiramente ao que preconiza João Paulo II (1987, n 28). E então, eis o quadro: há aqueles — os poucos que possuem muito — que não conseguem verdadeiramente 'ser', porque, devido a uma inversão da hierarquia dos valores, estão impedidos pelo culto do 'ter'; e há aqueles — os muitos que possuem pouco ou nada — que não conseguem realizar a sua vocação humana fundamental porque estão privados dos bens indispensáveis.

Quando o ato humano não se realiza enquanto comunhão à família humana, negligencia a própria existência, quando o ato tem por finalidade o egoísmo/egolatria se nega a própria dignidade humana. O problema na recusa humana de ser o administrador dos desafios sociais é tal que se pode recorrer as palavras de Sen \& Kliskberg, (2010, p. 9) ao citarem Ghandi, segundo o qual "A diferença entre o que fazemos e aquilo que somos capazes de fazer bastaria para solucionar a maioria dos problemas do mundo".

Por isso, teorias de justiça se justificam a partir da necessidade de debater problemas em sistemas sociais e propor caminhos alternativos às injustiças. Para atender a essas demandas, tais abordagens lançam mão da razão para descrever aquilo que se propõe superar e determinar possíveis "caminhos de justiça". Deste modo, injustiça é tudo aquilo que foi apontado 
como tal e que poderia ter sido evitada e assim não foi feito, destarte, "uma calamidade seria um caso de injustiça apenas se pudesse ter sido evitada, em especial se aqueles que poderiam ter agido para tentar evitá-la deixaram de fazer” (Sen, 2011, p. $34)$.

No entanto, com frequência, as injustiças estão postas antes mesmo que se pudesse traçar o diagnóstico que torna possível prevenir que ocorressem, no geral, são injustiças velhas - culturas, o modo como as coisas acontecem -, assentadas na humanidade há tanto tempo que passamos a acreditar que são consequências naturais de uma organização social e cria-se um sentimento da naturalização das injustiças.

O sentimento de normalidade pode ser suficiente para que seja levada uma "vida normal" diante das injustiças, mas não é suficiente para que elas sejam resolvidas; acostumar-se não é sinônimo de solução, pelo contrário é banalizar um mal que já se tem conhecimento e deste modo consentir com seus efeitos. Uma injustiça é tudo aquilo que com razão poderia ser evitado antes mesmo que ocorresse ou que permanece acontecendo sem que se alcance uma solução.

Essas injustiças acontecem em nível social e é perpetuada pela ineficácia institucional, em ambiento público e privado, impossibilitando a superação da problemática. $\mathrm{Na}$ américa Latina a pobreza encontra substrato para se desenvolver nas profundas desigualdades sociais que lastreiam a história latino-americana e que afetam diretamente o modo de vida e as oportunidades de seus moradores, sendo isso, portanto, temática de competência e interesse estatal. Riberio (2019, p. 13) afirma que as pessoas têm melhores oportunidades quando o Estado, ao cumprir sua função social, disponibiliza serviços como "bom sistema educacional, creches, sistema de proteção para os trabalhadores, sistema de coleta de impostos progressivos [...] e outras formas de organizações e regras que favoreçam o bem estar social". Zeifert \& Berton (2021, p. 859) Reforçam que "a adoção por alguns Estados a determinados modelos políticos e econômicos, os quais têm como prioridade o crescimento econômico, e não o desenvolvimento humano, nas suas diferentes dimensões, são causas da origem de inúmeras desigualdades, e dão ensejo a um cenário que viabiliza o surgimento de novas."

Quando se apresenta a diferença entre o que fazemos e nossa capacidade de fazer, se está falando de omissão. Omitimos nosso fazer em direção a construção de um processo de governança global, quando nossas ações diárias de solidariedade, de subsidiariedade e da construção de um bem comum à nossa comunidade, são suprimidas por ações egoístas. A diferença entre o que fazemos e a nossa capacidade de fazer, denota nossa vertente que corrompe a vivência, no sentido de reconhecer que o ser humano é um ser de sociabilidade, de economicidade e de parentalidade, todavia, essas dimensões se realizam como família humana.

Quando a cultura de vida e vivência não propícia a devida capabilidade à pessoa, há um desvio que não permite ao ser humano compreender sua potência de administrar as necessidades, as possibilidades e os subsídios que se tem a disposição. Para Sen, "Seja como for, com o desenvolvimento da tendência antiética, quando as comparações interpessoais de utilidade passaram a ser evitadas na economia do bem-estar, o critério sobrevivente foi a otimalidade de Pareto" (Sen, 1999, p. 47), não se deseja ver pessoas enquanto utilidade, mas em sua dignidade.

O autor segue afirmando que não se olha para trás com o objetivo de saber o que há de errado com o ser humano, mas para perceber o movimento que as pessoas realizam para avançar em direção do que é necessário aprender. Ainda segundo o autor, não se é movido pelo mal, ou pela quantidade de mal, mas pela esperança que alicerça as atitudes e práxis de vida e vivência das pessoas em direção ao nosso futuro, estamos aos poucos edificando a história humana, isto é, aprendendo e edificando o nosso jeito de administrar. De acordo com este prospecto é necessário observar que "Um estado pode estar no ótimo de Pareto havendo algumas pessoas na miséria extrema e outras nadando em luxo, desde que os miseráveis não possam melhorar suas condições sem reduzir o luxo dos ricos.” (Sen, 1999, p. 48).

A instrumentalização é chave das patologias que provocam a obsessão, a avareza e negligência. O humano cria valores absolutos - mitologias, que direcionam seu agir e o afasta do Ser. O consumismo e a descartabilidade das relações, são 
patológicas, induzem as pessoas a viverem em egolatrias, processos de avarezas e individualismo, por isso a aparência de beleza torna a mercadoria em algo que seduz a pessoa humana mediante o esforço necessário para obtê-la, para Francisco $\left(2013, n^{\circ} 2\right)$ "Quando a vida interior se fecha nos próprios interesses, deixa de haver espaço para os outros, já não entram os pobres, [...], já não se goza da doce alegria do seu amor, nem fervilha o entusiasmo de fazer o bem".

Em sociedades marcadas pelo consumismo e pela radicalização do capitalismo o que se observa é o rapto ideológico das necessidades e dos desejos. Necessidade e desejo são poderosos impulsos constitutivos da estrutura humana e estão constantemente definindo a maneira como agimos. Por isso mesmo, os arranjos religiosos e filosóficos quase sempre produzem dogmas considerando a existência dessas duas forças que se movem nas pessoas, seja para rejeitá-las como sinônimo de pecado ou seja para transformá-las em potência criadora. Os desejos e as necessidades podem ter seu conteúdo definido por um conjunto extenso de fatores, sejam sociais, ambientais, culturais, fisiológicos.

Ainda, é possível exercer o controle sobre seres desejantes na medida que ele é abastecido e recompensado com aquilo que deseja, logo após desempenhar uma atividade que é condição para a recompensa, ou seja, por meio de uma relação de reforço positivo. Dito isso, tem-se os ingredientes essenciais para que os desejos e as necessidades sejam utilizados como forma de controle pelo sistema econômico hegemônico, na medida que o conteúdo e objetos que se desejam são mercadorias, produtos e serviços, mas também posições, cargos e poder de maneira que as pessoas passam a perseguir tais fins. Raymond Guess (2008, p. 162) por sua vez reforça que "muitas de nossas necessidades e desejos em uma sociedade capitalista são falsos" e, por isso, continua "nos encontramos presos a padrões de comportamento que reproduzem o sistema capitalista que os produz".

Necessidades e desejos abstratamente considerados não são intrinsecamente bons ou maus, pode-se afirmar que, inclusive, são moralmente neutros, de maneira que uma sociedade desejante é uma sociedade com grande potencial. No entanto, impõem-se examinar o conteúdo de determinados desejos e julgá-lo pelo prisma crítico da ética e da primazia da dignidade da pessoa humana. De maneira que se conclua que não há respaldo racional desejar que uma nação se desenvolva economicamente em detrimento de outras, que um grupo de pessoas alcance melhores posições em virtude da defasagem de oportunidade dos demais, ou perseguir objetivos contraditório como a acumulação infinita de capital.

Nesse quesito, o individualismo potencializou e estendeu a novos territórios os limites dos desejos e necessidades que, num dado momento foi o que tornou possível a sobrevivência humana em contextos precários, para a acumulação material irracional, nem que pra isso seja necessário que parte das pessoas não tem nem suficiente para sobreviver. Guess (2008, p. 166), ao abordar o tema, comenta que "Uma vez que essas "falsas" necessidades são adquiridas, elas estabilizam o regime $[\ldots] "$.

No diminuto compartimento em que a economia do bem-estar ficou confinada, com a otimalidade de Pareto como o único critério de julgamento e o comportamento autointeressado como única base de escolha, o campo para dizer algo interessante em economia do bem-estar tornou-se reduzidíssimo. (Sen, 1999, pp. 49-50).

Kant já enfatizava que o sujeito é autônomo na medida que se serve de sua própria razão para determinar suas vontades e, a forma de fazer isso com real autonomia é desvincular a produção dessas vontades de experiências empíricas que, frequentemente, são influenciadas pelas paixões; pessoas apaixonadas não são "kantianamente livres" e, de fato não o são, mas nem por isso o que se pede é que deixem de se apaixonar. Por isso, o que se propõe é que se resgate um olhar para as consequências dos desejos no mundo ao mesmo tempo que reavalie sua qualidade moral.

Quando o humano se move em direção ao trabalho, deve mover-se como elemento estruturante de uma vida em parentalidade, em sociabilidade e em economicidade e, não com preceitos de acumular para além da necessidade, quando o trabalho se centra apenas no autointeresse, ou mesmo de forma exclusiva à parentalidade - familismo, a pessoa humana perde 
sua concepção de unidade. Sob os preceitos do possessivismo, para Pio XI (1931, nº II, 1),

A própria natureza exige a repartição dos bens em domínios particulares, precisamente a fim de poderem as coisas criadas servir ao bem comum de modo ordenado e constante. Este princípio deve ter continuamente diante dos olhos, quem não quer desviar-se da rata senda da verdade.

É importante edificar uma forma de administrar a vida e a vivência humana, e para tanto se faz necessário tecer sempre indagações, a exemplo de: como o que se deseja obter pode incapacitar e/ou impossibilitar a economicidade das outras pessoas? Verdadeiramente se está, enquanto humanidade, necessitados de compreender uma nova forma de viver, uma nova sabedoria. Francisco (2019) ressalta que é preciso cultivar uma cultura de paz, onde as pessoas possam se inspirar a exercer uma economicidade e uma sociabilidade "que faz viver e não mata, inclui e não exclui, humaniza e não desumaniza, cuida da criação e não a devasta".

Para Lovo (2020, p. 21), "não é o que se tem, é quantos vivem bem com o que se tem, sem que para isso outros tenham vivido, vivam, ou venham a viver mal", neste sentido, movimenta-se a esta intencionalidade de compreender a práxis de vida e vivência, não se trata de uma vontade de impor 'modelos', mas de propiciar a formação da consciência, zelando assim da capabilidade humana de modo que se possa "pôr em prática um modelo econômico novo, fruto de uma cultura da comunhão, baseado na fraternidade e na equidade" (Francisco, 2019), por isso João Paulo II (1991, nº 6) enfatiza que:

O trabalho pertence assim à vocação de cada pessoa; mais, o homem exprime-se e realiza-se na sua atividade laborativa. Simultaneamente o trabalho tem uma dimensão social, pela sua íntima relação quer com a família, quer com o bem comum, 'porque pode-se afirmar de verdade que o trabalho dos operários é o que produz as riquezas dos Estados'.

O estado não pode ser possessivo, nem despertar a possessividade nas pessoas, mas sim, conscientizar as pessoas para que possam administrar as necessidades, as possibilidades e os subsídios, bem como contribuir para a correspondência entre os povos das diferentes nações, até que se tornem unidos, não como domínio ou submissão, mas como correspondentes que se despertam para um novo horizonte: a governança global, o modo de administrar esperançado à vida humana, "seria um grande absurdo dedicar muita atenção ao tema da ética se efetivamente considerações éticas nunca afetassem o comportamento real das pessoas" (Sen, 1999, p. 68).

Nesse sentido, se faz necessário a orientação sobre a direção do desenvolvimento humano, para superar a necessidade de desenvolvimento participativo e compartilhado. A isso, se prediz a formação da consciência de pessoa. Observa-se que enquanto o pensar não for em função do todo, o agir será um censurador de outra liberdade, é preciso que a governança global apresente seus objetivos de desenvolvimento sustentável para que se possa compreender a necessidade de administrar o ambiente particular de vida, sem colocar em risco o ambiente do outro. Pensar a governança global, significa pensar nossa casa comum, de modo que cada cultura venha a contribuir para que cada pessoa seja tudo em todos, para que o agir seja libertador, isto é, deve haver a compreensão de que o ser humano vive em sociabilidade, em economicidade e em parentalidade.

Fomenta-se a distância entre economia e ética de modo a compreender o conflito, e ao mesmo tempo afirmar que esse impasse impacta decisivamente o comportamento humano, enquanto resultados preconiza-se a importância de compreender ética e economia enquanto unidade, propiciadora de motivação ao comportamento. Neste sentido, há a necessidade de ouvir a verdade que habita o próprio ser humano, e em virtude dessa verdade que é boa, bela e verdadeira, a pessoa se abre aos princípios de subsidiariedade, de bem comum e de solidariedade. Isto é, elucidar a capabilidade de reconhecer a necessidade de governança global se aplica à necessidade de se reconhecer a própria verdade da vida humana. 


\section{Considerações Finais}

O fato de pensar a sociedade ideal não pode limitar o agir humano, em face suas limitações, a capacidade de diagnosticar é, evidentemente, superior a capacidade humana de realizar. Há, contudo, que se utilizar a capacidade de diagnosticar, seja por intermédio da ciência ou das percepções pessoais, para que se direcione à sociedade de modo a promover a governança global com base na razão e na ética.

Neste sentido, é notória a importância de compreender a ética como elemento formador e constituído da razão, da forma como cada pessoa pensa seu estar e seu agir no mundo. Isso é dado porque, quando a razão se torna desvinculada de uma formação ética, o ser humano precisa ser agente responsável por salvaguardar a práxis que possibilite a governança global. Assim, faz-se necessário que haja uma moralidade universal que nos possibilite compreender, uns aos outros, como semelhantes, para que se possa assim viver a solidariedade e a economicidade que proponha o desenvolvimento sustentável.

É necessário agir e garantir as pessoas, em situação de vulnerabilidade, melhores condições para que possam se tornar autônomos dados os processos de subsidiariedade. Para que isso ocorra é basilar compreender a razão e a ética como elementos indissociáveis que provem, a depender da educação e formação das pessoas, uma práxis que promove a governança global.

O Estado, enquanto estágio de desenvolvimento e ordenamento de uma sociedade, é fator de elevada importância para a promoção da sustentabilidade, haja vista que, por intermédio das instituições pode alcançar muitas pessoas e assim promover a educação que dinamize a práxis autônoma de um desenvolvimento. Neste sentido, à estas instituições não interessam, verdadeiramente, a forma e a estruturação social, mas sim a formação da consciência das pessoas, para que estas possam agir e decidir atentamente sobre como administrar as necessidades, as possibilidades e os subsídios que se tem a disposição.

\section{Referências}

Brasil. Constituição da República Federativa do Brasil. (1988), Brasília, DF, Senado Federal. http://www.planalto.gov.br/ccivil_03/co nstituicao/constituicao.htm.

Francisco. (2019). Carta do Papa Francisco para o evento “Economy of Francisco”. Libreria Editrice Vaticana. http://w2.vatican.va/content/francesco/pt/lette rs/2019/documents/papa-francesco_20190501_giovani-imprenditori.html.

Francisco. (2013). Evangelii Gaudium. Roma: Libreria Editrice Vaticana. https://www.vatican.va/content/francesco/pt/apost_exhortations/documents/papafrancesco_esortazione-ap_20131124_evangelii-gaudium.html.

Gil, A. C. (2017). Como Elaborar Projetos de Pesquisa. (6a ed.), Atlas.

Guess, R. (2008). A dialética e o impulso revolucionário. In: RUSH, Fred. Teoria Crítica. Aparecida, Ideias e Letras. p. 135-174.

João Paulo II. (1991) Centesimus annus. Roma: Libreria Editrice Vaticana. http://w2.vatican.va/content/john-paul-ii/pt/encyclicals/documents/hf_jpii_enc_01051991_centesimus-annus.html.

João Paulo II. (2004) Compêndio da Doutrina Social da Igreja. Roma: Libreria Editrice Vaticana. http://www.vatican.va/roman_curia/pontifical_councils/justpeace/documents/rc_pc_justpeace_doc_20060526_compendio-dott-soc_po.html.

João Paulo II. Sollicitudo rei socialis. (1987). Libreria Editrice Vaticana. http://w2.vatican.va/content/john-paul-ii/pt/encyclicals/documents/hf_jpii_enc_30121987_sollicitudo-rei-socialis.html.

João XXIII. (1961). Mater et magistra. Libreria Editrice Vaticana. http://w2.vatican.va/content/john-xxiii/pt/encyclicals/documents/hf_jxxiii_enc_15051961_mater.html.

João XXIII. (1963). Pacem in Terris. Libreria Editrice Vaticana. http://w2.vatican.va/content/john-xxiii/pt/encyclicals/documents/hf_jxxiii_enc_11041963_pacem.html.

Kant, Il. (2015). Crítica da razão pura. (4a ed.), Vozes.

Kant, I. (2019). Fundamentação da Metafísica dos Costumes. São Paulo: Martin Claret.

Lovo, O. A. (2020) Alteridade humana e contingência no Reino. Revista Caminhando 25(3), 21-36, https://doi.org/10.15603/21763828/caminhando.v25n3p21-36.

Pio XI. Quadragesimo anno. (1931). Roma: Libreria Editrice Vaticana, 1931. https://w2.vatican.va/content/pius-xi/pt/encyclicals/documents/hf_pxi_enc_19310515_quadragesimo-anno.html. 
Research, Society and Development, v. 10, n. 16, e298101623817, 2021

(CC BY 4.0) | ISSN 2525-3409 | DOI: http://dx.doi.org/10.33448/rsd-v10i16.23817

Ribeiro, C. A. C. (2019). A dimensão Social das Desigualdades. Appris, 2019.

Sen, A., \& Klisberg, B. (2010). As pessoas em primeiro lugar: A ética do desenvolvimento e os problemas do mundo globalizado. (B. Ajzemberg, \& C. L. Silva, Trads.) São Paulo, São Paulo, Brasil: Companhia das Letras.

Sen, A. (2011). A ideia de justiça. Companhia das Letras.

Sen, A. (2010). Desenvolvimento com liberdade. Companhia das Letras. Tradução: Laura Teixeira Motta.

Sen, A. (1999). Sobre ética e economia. (L. T. Motta, Trad.) Companhia das Letras.

Severino, A. J. (2016). Metodologia do Trabalho Científico (24a ed.) Cortez.

Weber, T. (2013). Ética e Filosofia do Direito: autonomia e dignidade da pessoa humana. Vozes.

Zeifert, A. P. B., \& Berton, D. C. (2021). As desigualdades histórico-estruturais nas sociedades latino americanas e as políticas sociais de promoção da igualdade. Quaestio Iuris, 14(2). 857-881. https://www.e-publicacoes.uerj.br/index.php/quaestioiuris/article/view/53494. 